\title{
ANALISIS BEBAN KERJA TERHADAP STRES KERJA DAN KINERJA KARYAWAN PADA PT INDOMARCO ADI PRIMA BALIKPAPAN
}

\author{
Andi Surayya Mappangile ${ }^{1}$, Yohana Cornelia Pontoluli², Muhammad Zefri ${ }^{3}$ \\ Program Studi Keselamatan dan Kesehatan Kerja, Fakultas Vokasi, \\ Universitas Balikpapan ${ }^{1,2,3}$, \\ Email : andisurayya@uniba-bpn.ac.id1,yohanacornelia95@gmail.com², \\ muhammad.zefri30@gmail.com³
}

\begin{abstract}
ABSTRAK
Salah satu aspek yang mempengaruhi keberhasilan suatu perusahaan adalah dengan melihat prestasi kerja karyawan. Prestasi kerja dapat dilihat dari kualitas kerja seperti ketelitian, kerapian dan kedisiplinan karyawan melaksanakan tugas pekerjaan, selain itu tercapainya target merupakan suatu pretasi kerja. Dalam pelaksanaannya setiap karyawan memiliki beban kerja yang berbeda-beda. Jika kemampuan pekerja lebih rendah daripada tuntutan pekerjaan maka akan mucul kelelahan yang mengakibatkan stres kerja. Tujuan penelitian ini adalah untuk mengetahui apakah ada pengaruh beban kerja terhadap stres kerja dan kinerja karyawan. Jenis penelitian ini merupakan penelitian kuantitatif. Jumlah sampel yang digunakan adalah 75 karyawan (total sampling) di PT Indomarco Adi Prima Balikpapan. Hasil penelitian menunjukkan bahwa 31 orang $(41,3 \%)$ memiliki beban kerja berat, 41 orang $(54,5 \%)$ memiliki tingkat stres kerja sedang, dan 47 orang $(62,7 \%)$ kinerjanya tidak baik. Hasil penelitian ini menyatakan bahwa beban kerja berpengaruh terhadap stres kerja dan kinerja karyawan, dengan diperoleh nilah signifikansi $\mathrm{p}<0,05$ yaitu sebesar 0,000.
\end{abstract}

Kata Kunci: Beban, Stres, Kinerja Karyawan.

\begin{abstract}
One aspect that affects the success of a company is to look at employee work performance. Work performance can be seen from the quality of work such as accuracy, neatness and discipline of employees carrying out work tasks, in addition to achieving the target is a work achievement. In practice, each employee has a different workload. If the ability of workers is lower than the demands of the job, fatigue will occur which results in work stress. The purpose of this study was to determine whether there is an influence of workload on work stress and employee performance. This type of research is quantitative research. The number of samples used was 75 employees (total sampling) at PT Indomarco Adi Prima Balikpapan. The results showed that 31 people $(41.3 \%)$ had heavy workloads, 41 people $(54.5 \%)$ had moderate work stress levels, and 47 people (62.7\%) had poor performance. The results of this study stated that workload influences work stress and employee performance, with a significance value of $p<0.05$ which is equal to 0.000 .
\end{abstract}

Keywords: Burden, Stress, Employee Performance. 


\section{PENDAHULUAN}

Salah satu aspek yang mempengaruhi keberhasilan suatu perusahaan adalah dengan melihat prestasi kerja karyawan. Prestasi kerja dapat dilihat dari kualitas kerja seperti ketelitian, kerapian dan kedispilinan karyawan melaksanakan tugas pekerjaan, selain itu tercapainya target merupakan suatu pretasi kerja.

Setiap pekerjaan yang dikerjakan karyawan dapat memberikan beban tersendiri bagi pelakunya baik beban fisik, bebab mental, maupun sosial. Dalam pelaksanaannya setiap karyawan memiliki beban kerja yang berbeda-beda. Beban kerja seseorang sudah ditentukan dalam bentuk standar kerja perusahaan menurut jenis pekerjaannya. Beban kerja dapat terjadi dalam tiga kondisi. Pertama, beban kerja sesuai standar. Kedua, beban kerja yang terlalu tinggi (over capacity). Ketiga, beban kerja terlalu rendah (under capacity).

Peraturan Menteri dalam Negeri No. 12/2008 menyatakan bahwa beban kerja merupakan besaran pekerjaan yang harus dipikul oleh suatu jabatan / unit organisasi dan merupakan hasil kali antara volume kerja dan norma waktu. Jika kemampuan kemampuan pekerja lebih rendah daripada tuntutan pekerjaan maka akan muncul kelelahan yang lebih. Menurut Badan Eksekutif untuk Kesehatan dan
Keselamatan selama tahun 2016-2017 sebanyak 12,5jt jam kerja hilang karena stres, depresi dan kegelisahan. Data Perhimpunan Dokter Spesialis Kedokteran Jiwa Indonesia (PDSKI) pada tahun 2018, dikisaran $15-30 \%$ setiap tahunnya terdapat pegawai yang mengalami stres. Hal ini menyebabkan menurunnya produktiviatas karyawan yang berujung kerugian terhadap perusahaan.

Stres adalah suatu kondisi keadaan seseorang mengalami ketegangan karena adanya kondisi yang mempengaruhinya, kondisi tersebut dapat diperoleh dari dalam diri seseorang maupun lingkungan diluar diri seseorang (Astianto, A. 2014). Sedangkan stres kerja pada karyawan menurut Saam dan Wahyuni (2013) adalah ketidakmampuan individu dalam memenuhi tuntutan tugas pekerjaan sehingga ia merasa tidak nyaman dan tidak senang. Stres kerja yang dialami oleh karyawan akan merugikan perusahaan yang bersangkutan karena kinerja yang dihasilkan menurun.

PT Indomarco Adi Prima merupakan perusahaan yang bergerak dibidang distributor dengan berbagai jenis pekerjaan. Dalam usahanya PT Indomarco Adi Prima memberikan pelayanan yang paling responsif dan dapat di andalkan guna untuk menghadapi berbagai kendala dan persaingan yang semakin ketat. Hal ini 
menyebabkan karyawan dihadapkan dengan berbagai kondisi, dimana mereka dituntut untuk bekerja sesuai dengan standar yang ditentukan oleh perusahaan serta diwajibkan untuk mencapai target yang sudah ditetapkan pada masingmasing unit pekerjaan. Sementara disisi lain karyawan memiliki kebutuhan dan keinginan yang perlu mendapat perhatian dari perusahaan. Kondisi tersebut tentunya akan menimbulkan stres pada karyawan yang dapat juga berpengaruh terhadap kinerja karyawan.

Berdasarkan pemamparan tersebut peneliti ingin mengetahui apakah ada pengaruh beban kerja terhadap stres kerja dan kinerja karyawan di PT Indomarco Adi Prima Balikpapan tersebut. Selanjutnya penelitian ini akan diberi judul : "Pengaruh Beban Kerja Terhadap Stres Kerja dan Kinerja Karyawan PT Indormarco Adi Prima Balikpapan”.

\section{METODE PENELITIAN}

Jenis penelitian ini adalah penelitian kuantitatif. Jumlah sampel yang digunakan adalah 75 orang karyawan yang terdiri dari 35 orang Pick-Pack, 25 orang Deliveryman, dan 15 orang Goodown Keeper di PT Indomarco Adi Prima Balikpapan. Penelitian ini menggunakan data primer berupa kuesioner, kuesioner untuk mengukur beban kerja yang telah diuji validitasnya oleh Anggit Astianto (2014), kuesioner Depression Anxiety Stress Scale (DASS 42) sebagai alat untuk mengukur stres kerja, dan kuesioner untuk mengetahui kinerja karyawan yang telah diuji validitasnya oleh Reny Suharyati (2017). Sedangkan untuk data sekunder berupa data profil perusahaan, dan jumlah karyawan PT Indomarco Adi Prima Balikpapan.

\section{HASIL PENELITIAN DAN PEMBAHASAN}

\section{A. Karakteristik Responden}

1. Distribusi frekuensi responden berdasarkan unit pekerjaan

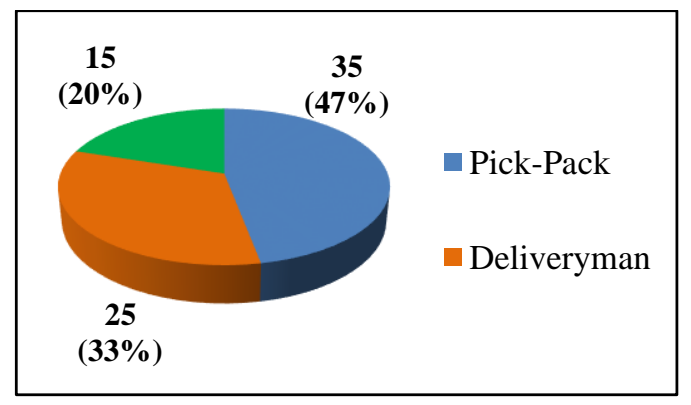

Gambar 4.1 Distribusi Frekuensi Unit Pekerjaan.

2. Distribusi frekuensi berdasarkan status pernikahan

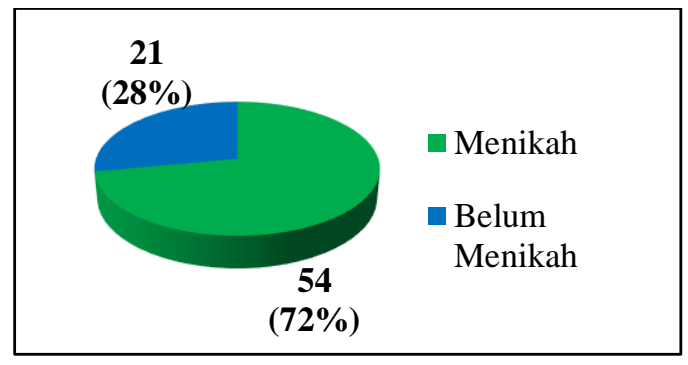

Gambar 4.2 Distribusi Frekuensi Status Pernikahan. 
3. Distribusi frekuensi berdasarkan jenis kelamin

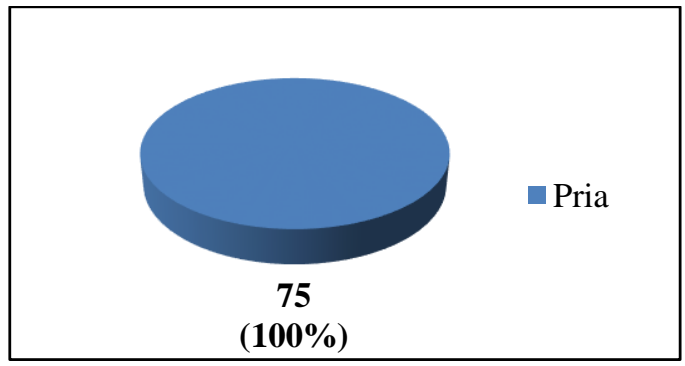

Gambar 4.3 Distribusi Frekuensi Jenis Kelamin.

4. Distribusi frekuensi berdasarkan jenis pendidikan

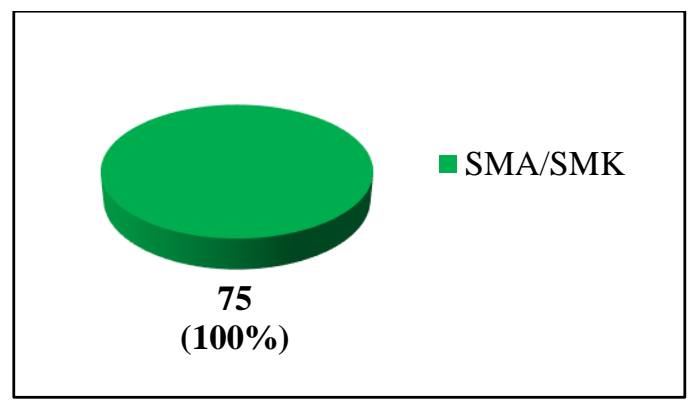

Gambar 4.4 Distribusi Frekuensi Jenis Pendidikan.

SMA/SMK sebanyak 75 karyawan dengan presentase $100 \%$.

5. Distribusi frekuensi berdasarkan umur responden

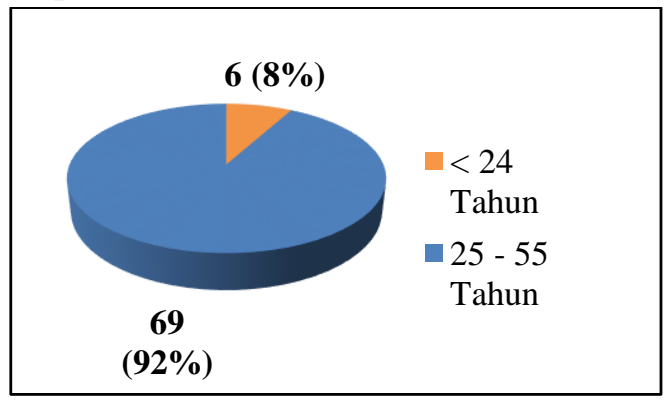

Gambar 4.5 Distribusi Frekuensi Umur Responden.
6. Distribusi frekuensi berdasarkan masa kerja

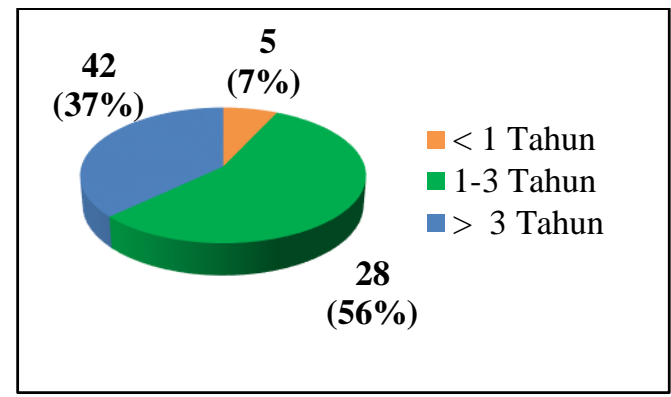

Gambar 4.6 Distribusi Frekuensi Masa Kerja.

\section{B. Hasil Analisis Univariat \\ 1. Beban Kerja}

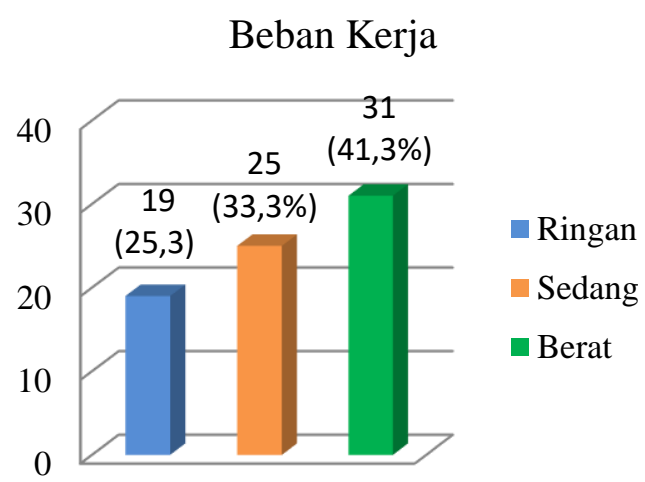

Gambar 4.7 Distribusi Frekuensi Beban Kerja.

Berdasarkan gambar 4.7 secara umum distribusi frekuensi beban kerja karyawan didominasi pada kategori berat yaitu sebanyak 31 responden dengan presentase 41,3\% sedangkan pada kategori sedang sebanyak 25 responden dengan presentase $33,3 \%$ dan pada kategori ringan sebanyak 19 responden dengan presentase $25,3 \%$. 
Berdasarkan tabel 4.12 secara umum

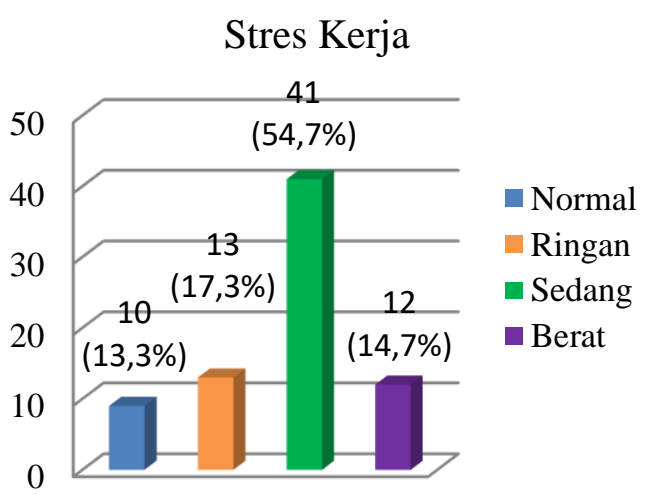

Gambar 4.8 Distribusi Frekuensi Stres Kerja

Berdasarkan gambar 4.8 secara umum distribusi frekuensi tingkat stres kerja karyawan didominasi pada kategori sedang yaitu sebanyak 41 responden dengan presentase $54,7 \%$ sedangkan kategori berat 12 responden dengan presentase $16,0 \%$ dan pada kategori ringan sebanyak 13 responden dengan presentase $17,3 \%$ serta pada kategori normal sebanyak 9 dengan presentase $12,0 \%$.

3. Kinerja Karyawan

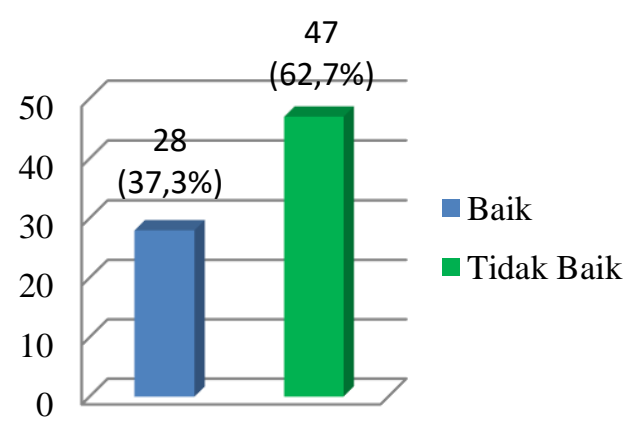

Gambar 4.9 Distribusi Frekuensi Kinerja Karyawan. distribusi frekuensi kinerja karyawan didominasi pada kategori tidak baik sebanyak 47 responden dengan presentase $62,7 \%$ sedangkan pada kategori baik sebanyak 28 responden dengan presentase $37,3 \%$.

\section{Hasil Analisis Bivariat}

1. Hasi Uji Chi Square

Tabel 4.1 Hasil Uji Chi Square Antara Beban KerjaDengan Stres Kerja

\begin{tabular}{|c|c|c|c|c|c|c|c|c|c|c|c|c|}
\hline \multirow{3}{*}{$\begin{array}{c}\text { Beban } \\
\text { Kerja }\end{array}$} & \multicolumn{8}{|c|}{ Stress Kerja } & \multirow{3}{*}{ Total } & \multirow{3}{*}{$\begin{array}{c}\text { Koefisien } \\
\text { Korelasi }\end{array}$} & \multirow{3}{*}{ Signifikansi } & \multirow{3}{*}{ Keterangan } \\
\hline & \multicolumn{2}{|c|}{ Normal } & \multicolumn{2}{|c|}{ Ringan } & \multicolumn{2}{|c|}{ Sedang } & \multicolumn{2}{|c|}{ Berat } & & & & \\
\hline & $\mathrm{n}$ & $\%$ & $\mathrm{n}$ & $\%$ & $\mathrm{n}$ & $\%$ & $\mathrm{n}$ & $\%$ & & & & \\
\hline Ringan & 9 & 47.4 & 10 & 52.6 & 0 & 0.0 & 0 & 0.0 & 19 & & 0,000 & \\
\hline Sedang & 0 & 0.0 & 3 & 12.0 & 22 & 88.0 & 0 & 0.0 & 25 & 0,000 & & Signifikan \\
\hline Berat & 0 & 0.0 & 0 & 0.0 & 19 & 61.3 & 12 & 38.7 & 31 & & $\mathrm{p}<0,05$ & \\
\hline Total & 9 & & 13 & & 41 & & 12 & & 75 & & & \\
\hline
\end{tabular}

Berdasarkan tabel 4.1 diatas diperoleh nilai koefisien korelasi sebesar 0,000 lebih kecil daripada 0,05 $(\mathrm{p}<0,05)$ maka artinya terdapat hubungan yang signifikan antara beban kerja dengan stres kerja. 
Tabel 4.2 Hasil Uji Chi Square Antara

Beban Kerja Dengan Kinerja

Karyawan.

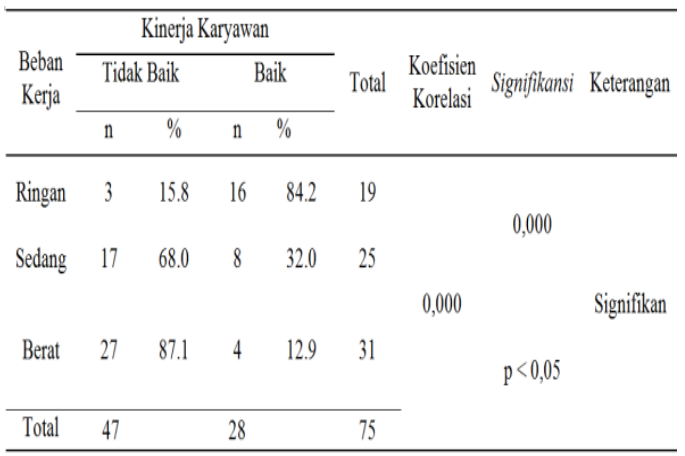

Berdasarkan tabel 4.2 diatas diperoleh nilai koefisien korelasi sebesar 0,000 lebih kecil daripada 0,05 ( $<<0,05)$ maka artinya terdapat hubungan yang signifikan antara beban kerja dengan kinerja karyawan.

\section{PEMBAHASAN}

Berdasarkan hasil penelitian diketahui bahwa karyawan memiliki beban kerja pada kategori berat dengan tingkat stres pada kategori sedang. Indikator yang menjadi potensi penyebab beban kerja berat adalah mengenai volume dan waktu kerja. Besarnya volume dengan waktu kerja yang tidak cukup, menyebabkan pekerjaan tidak dapat diselesaikan tepat waktu, sehingga karyawan harus menyelesaikan pekerjaan diluar jam operasional perusahaan. Beban kerja yang dirasa terlalu berat mempengaruhi kondisi fisik dikarenakan adanya jam kerja tambahan untuk menyelesaikan pekerjaan, hal tersebut dapat menjadi tekanan yang dapat memicu terjadinya stres kerja. Fakta yang ditemukan pada data kuesioner stres kerja, responden yang memiliki tingkat stres kerja sedang dan berat terlihat dari mereka yang sering marah karena hal sepele, bereaksi berlebihan, sulit untuk beristirahat, mudah merasa kesal, sulit mentolerir gangguan, mudah marah dan mudah tersinggung. Dibuktikan dengan hasil uji korelasi Chi Square pada tabel 4.1 bahwa terdapat hubungan antara beban kerja dengan stres kerja, dengan diperolehnya nilai koefisien korelasi $\mathrm{p}<$ 0,05 sebesar 0,000. Menurut T. Hani Handoko (Atmaji, L. 2011) menyatakan bahwa beban kerja yang berlebihan serta tekanan dan desakan waktu dapat menjadi faktor penyebab stres kerja karyawan.

Hasil penelitian terkait karyawan memiliki beban kerja pada kategori berat dengan kinerja karyawan pada kategori tidak baik. Indikator yang menjadi potensi penyebab beban kerja berat adalah mengenai volume dan waktu kerja. Besarnya volume dengan waktu kerja yang dirasakan karyawan tersebut menyebabkan pekerjaan tidak dapat diselesaikan tepat waktu, sehingga karyawan harus menyelesaikan pekerjaan diluar jam operasional perusahaan. Beban kerja yang dirasa terlalu berat mempengaruhi kondisi fisik karena adanya jam kerja tambahan 
untuk menyelesaikan pekerjaan tersebut, hal itu dapat menjadi tekanan yang dapat memicu terjadinya stres kerja pada karyawan yang mengakibatkan kinerjanya menurun. Fakta yang ditemukan pada data kuesioner kinerja karyawan, responden yang memiliki kinerja tidak baik terlihat dari mereka yang tidak memiliki rencana kerja yang menyeluruh dan berjuang untuk merealisasikan tujuan pekerjaannya, tidak nyaman dengan lingkungan kerjanya, kurang puas dengan hasil kerjanya, tidak tepat waktu dalam menyelesaikan pekerjaan, tidak memiliki inisiatif, tidak kreatif, kurang memanfaat waktu kosong untuk hal bermanfaat. Dibuktikan dengan hasil uji korelasi Chi Square pada tabel 4.2 bahwa terdapat hubungan antara beban kerja dengan kinerja karyawan, dengan diperolehnya nilai koefisien korelasi $\mathrm{p}<$ 0,05 sebesar 0,000. Menurut Moorhead dan Chung Megginson (Elok Rosyidah, 2017) menyatakan bahwa kinerja dipengaruhi oleh beberapa faktor, salah satunya adalah faktor kuantitas pekerjaan yang harus diselesaikan oleh karyawan.

Menurut UU No. 13/2003 pasal 77 ayat 1 menyatakan bahwa apabila bekerja selama 5 hari dalam 1 minggu maka jam kerjanya adalah 8 jam dalam 1 hari dan 40 jam dalam 1 minggu. PT Indomarco Adi Prima Balikpapan mempunyai jam kerja mulai pukul 08.00-17.00 dan 5 hari kerja.
Hasil penelitian ini sejalan dengan penelitian Aster Andriani (2014) yang menyatakan bahwa beban kerja berpengaruh terhadap stres kerja karyawan PT. Apie Indo Karunia.

Hasil penelitian ini sejalan dengan teori Huey dan Wickens (Andriani, A. 2014) menyatakan bahwa ketika beban kerja tinggi kesalahan akan muncul dari ketidakmampuan karyawan mengatasi tuntutan tugas. Beban kerja dan kinerja berpengaruh negatif dimana beban kerja meningkat maka kinerja akan menurun. Penelitian ini mendukung penelitian Shah et al., (2011) menyatakan bahwa peningkatan (rendah hingga medium) beban kerja dapat mengakibatkan penurunan kinerja. Penelitian ini menemukan pengaruh negatif antara beban kerja terhadap kinerja karyawan, sehingga apabila beban kerja meningkat, maka kinerja karyawan akan menurun.

\section{KESIMPULAN DAN SARAN}

1. Kesimpulan

Berdasarkan hasil penelitian yang telah di analisis menggunakan Chi Square dapat diambil kesimpulan sebagai berikut:

a. Beban kerja pada karyawan termasuk dalam kategori berat sebanyak 31 responden dengan presentase $41,3 \%$. 
b. Tingkat stres pada karyawan termasuk dalam kategori sedang sebanyak 41 responden dengan presentase $54,5 \%$.

c. Kinerja karyawan PT termasuk dalam kategori tidak baik sebanyak 47 responden dengan presentase $62,7 \%$.

d. Variabel beban kerja menunjukkan ada hubungan terhadap stres kerja karyawan dan variabel beban kerja juga menunjukkah ada pngaruh terhadap kinerja karyawan di PT Indomarco Adi Prima Balikpapan.

2. Saran

Berdasarkan kesimpulan diatas, maka peneliti memberikan saran sebagai berikut :

a. Perusahaan harus melakukan evaluasi terkait beban kerja dan kemampuan atau kapasitas pada karyawan.

b. Perusahaan mengadakan kembali kegiatan yang dapat menyegarkan baik jasmani ataupun rohani, diharapkan dengan kegiatan tersebut dapat mengurangi atau mencegah stres kerja.

c. Perusahaan memberikan apresiasi kepada karyawan seperti promosi, kenaikan gaji, ataupun bonus agar dapat memotivasi karyawan untuk meningkatkan kinerjanya.

\section{DAFTAR PUSTAKA}

Andriani, A. 2014. Pengaruh Beban Kerja Terhadap Stres Kerja dan Dampaknya Terhadap Kinerja Karyawan. Jurnal Ilmu Manajemen, Vol. 2, No. 2.

Astianto, Suprihhadi H. 2014. Pengaruh Stres Kerja Dan Beban Kerja Terhadap Kinerja Karyawan PDAM Surabaya. Jurnal Ilmu \& Riset Manajemen Vol. 3 No.7.

Manuaba, A. 2011, Ergonomi, Kesehatan dan Keselamatan Kerja. Dalam :Wigny Osvebroto, S \& Wiratno, SE, Eds, Procendings Seminar Nasional Ergonomi. PT. Guna Widya, Surabaya : 1-4.

Nabila, H. 2013. Pengukuran Hars dan Dass. Available from: https://www.scribd.com/docume nt/334065153/Pengukuran-HarsDan-Dass. [diakses tanggal 20 Oktober 2018].

Chung, Kae. E \& Megginson, Leon. Organisasi Behavior; Development Managerial, New York, Hopper, Publishar. 